\title{
Exposure to particulate matter and life loss from traveling by four different common commuting modes
}

Jinlong Zheng

Chang'an University

Zhaowen Qiu ( $\nabla$ qzw@chd.edu.cn )

Chang'an University https://orcid.org/0000-0003-4283-0224

\section{Research}

Keywords: Travel modes; Commuting exposure; TRAP; Life table method

Posted Date: May 13th, 2020

DOI: https://doi.org/10.21203/rs.3.rs-27757/v1

License: (c) (1) This work is licensed under a Creative Commons Attribution 4.0 International License.

Read Full License 


\section{Abstract \\ Objective}

Traffic-related air pollution (TRAP) has an adverse effect on commuters. The primary aim of this article was to make a comparison of PM exposure among four common transportation modes, analyze various influencing factors for specific modes, and evaluate public health effects caused by commuting exposure.

\section{Method:}

The experimental database was integrated for the four modes' 336 trips and 13 volunteers' heart-rate data. Basic descriptive statistics were used to compare PM exposure levels, and multivariable linear regression model and Spearman correlation analysis were adopted to explore major influences on pollution concentration among the different modes. In human health evaluations, the inhalation dose model and life table method were employed to obtain inhaled dose and years of life expectancy loss (YLE).

\section{Results}

The results indicated that higher $\mathrm{PM}$ exposure was found in cycling (average $\mathrm{PM}_{10}, \mathrm{PM}_{2.5}$ and $\mathrm{PM}_{1.0}$ of $114.35,72.37$ and $56.51 \mu \mathrm{g} / \mathrm{m}^{3}$, respectively), followed by bus $\left(116.29,67.60\right.$ and $51.12 \mu \mathrm{g} / \mathrm{m}^{3}$ for the same pollutants, respectively), and then taxi $\left(97.61,58.87\right.$ and $\left.45.11 \mu \mathrm{g} / \mathrm{m}^{3}\right)$, and the lowest concentrations appeared in subways $\left(55.86,46.20\right.$ and $\left.40.20 \mu \mathrm{g} / \mathrm{m}^{3}\right)$. Background pollution concentration and relative humidity were the staple determining factors on PM exposure according to the analysis outcomes. The greatest YLE loss was found for cycling, and could result in per capita 5.51-6.43 months of life expectancy loss for the 15-64 age group.

\section{Conclusions}

Given the higher average PM concentration for cycling, substituting other modes (like subway) for cycling could reduce adverse health effects during severely polluted periods, before the completion of local dedicated infrastructure projects that might reduce bicyclists' exposure. $\mathrm{PM}_{2.5}$ levels in taxi cabins were decreased greatly when the vehicles were powered by CNG or methanol as compared to traditional fuels, indicating that implementing energy structure strategies such as vigorously promoting clean energy could effectively reduce pollution emissions and residents' exposure.

\section{Introduction}


Air pollution has become one of the most serious problems facing human society in recent years. Substantial studies have revealed that air pollution exposure is associated with poor human health outcomes, causing adverse effects on the respiratory system [1, 2], cardiovascular system [3, 4], and reproductive system $[5,6]$. One specific type of pollution is exposure to particulate matter (PM), and this type of exposure, especially during commuting periods, has attracted many researchers' attention, as measured PM concentration in the traffic microenvironment is always higher than the background concentration, causing a significant fraction of daily PM exposure to occur during commuting [7], despite its short duration (1-1.5 h per day). Ranft et al. [8] observed that long-term exposure to traffic-related air pollution was associated with mild cognitive impairment. Through a survey of 183 traffic policemen, Tan et al. [9] found that exposure to high air pollution could lead to metabolism adaptation and possibly increase morbidity from cardiovascular disease and diabetes mellitus. Zhu et al. [10] proved the role of $\mathrm{PM}_{2.5}$ in premature birth, and revealed that exposure of pregnant women to $\mathrm{PM}_{2.5}$ at an average AQI (Air Quality Index) above 50 could increase this risk. Previous studies have investigated commuter exposure to particulate matter for different commuting modes, such as subway, bus, car, bicycle, and walking [1114]. And several studies have focused on other travel vehicles such as motorcycles [15] and autorickshaws [16], as well as related urban traffic microenvironments [17]. Aiming to obtain more detailed and comprehensive information on air pollution exposure, much of the published literature has focused on a single commuting mode or on comparisons between different modes. Proposals have also been made for decreasing pollution exposure, such as separated bicycle lanes [18, 19], or alternate ventilation modes (e.g., air-conditioning recirculation) in private cars [20]. Moreover, although previous studies have found discrepancies between different modes, these may have been caused by other factors not taken into consideration (e.g., economic factors, vehicle composition, etc.) [21, 22]. Taxi operating performance, for example, can decline rapidly because of high average annual mileage. The taxi industry, though, is playing an indispensable role in daily life, and more attention should been paid to air pollution exposure in the cabin of a taxi. Cycling is also becoming an increasingly popular mode of transportation in China, since it produces no emissions and alleviates traffic congestion. However, published literatures have shown that exposure to pollution by traveling adjacent to a main road, and a higher respiration rate, could cause more serious pollution exposure during cycling $[18,23,24]$. We studied the air pollution exposure for both taxis and bicycles, in order to compare them with other conventional modes (subway and bus) and provide some scientific basis for choosing a suitable mode to lessen pollution exposure.

Research studies always adopt exposure dose as a means of accurately evaluating pollution exposure. Whether a distance-based or duration-based method is used, though, exposure calculations are ultimately dependent on the per-minute ventilation rate (VR), which is defined as the amount of air inhaled per minute [25]. However, since breathing-rate measurement devices seldom, if ever, produce accurate results, most previous studies have chosen default respiration rates based on an activity's predetermined intensity $[12,26]$. Hardly any studies, however, have monitored the breathing rates of experimental subjects during sampling periods, for different commuter modes. In this study, the heart rate (HR) was used as an indirect method of calculating breathing rate, to improve the accuracy of exposure evaluation. 
While studies on traffic-related air pollution exposure have for decades adopted common evaluation indices, such as pollution concentration and inhaled dose, as well as lung deposited surface area (LDSA) $[27,28]$, few such studies, to our knowledge, have attempted to calculate years of life expectancy (YLE) in order to study the association between pollution exposure and health, using practical measurement campaigns.

This study was conducted in Xi'an, one of China's most populous cities, with approximately 9 million (in 2018) residents in an area of $3578 \mathrm{~km}^{2}$. The main public transportation modes (subway, bus, taxi and bicycle) were studied, referencing the report released by Amap which reported that the public travel index of Xi'an was the largest among 50 monitored cities in 2018 (https://report.amap.com). The increase in the proportion of travel by public modes indicated a growing need for accurate evaluation of pollutant exposure during the process of commuting. In this study, personal exposure to particulate matter during commuting by these four commuting modes was monitored, along predetermined routes, and the heterogeneous distribution of fine particulate matter $\left(\mathrm{PM}_{1.0}, \mathrm{PM}_{2.5}\right.$ and $\left.\mathrm{PM}_{10}\right)$ in different transportation microenvironments (shelters and boarding stations of typical modes) was investigated. The study also compared total exposure among the four modes in two different seasons (summer and winter). The results we obtained in this study, including estimates of population daily dose and YLE loss, could provide the theoretical basis for epidemiologic research and the development of effective policies for exposure mitigation.

In order to fill in the research gaps mentioned above, the aims of our study were to (i) obtain real-world PM exposure levels for specific commuting modes using measurement experiments; (ii) identify the local factors that significantly influenced PM exposure for these different modes; (iii) calculate more precise commuting exposure doses by determining the relationship between heart rate and respiratory rate; and (iv) evaluate the YLE loss attributable to this exposure, for a relatively large population sample, under certain hypothetical situations.

\section{Materials And Methods}

\section{Route characteristics}

Xi'an $\left(34^{\circ} 02^{\prime} \mathrm{N}, 108^{\circ} 09^{\prime} \mathrm{E}\right)$, the largest city in northwest China, is a typical northern city located in the center of Guanzhong Plain. It has a temperate semi-humid monsoon climate with an annual average temperature of $15.6^{\circ} \mathrm{C}$ and wind speed of approximately $2.1 \mathrm{~m} \cdot \mathrm{s}^{-1}$ (http://tjj.shaanxi.gov.cn/).

In order to evaluate the exposure levels for all four commuting modes (subway, bus, taxi and bicycle), the measurement campaign was conducted at roads where all of these modes are used on a regular basis. And, focusing on the scale of the urban area, two specific roads that could represent the fundamental road characteristics in Xi'an were chosen for this study (see Fig. 1). Route 1, located on the Chang'an Middle Road, is an arterial road connecting the center of the city and " 2 ring roads"; it is one of the busiest roads in Xi'an. Route 2 (Guang'an Road) is a section of the North 2 ring road extending eastward. There 
were some differences between the characteristics of the two roads we chose, because of geographic differences such as road configuration, traffic flow and composition, land-use types, etc.

\section{Study design and data acquisition}

The experiment comprised two phases based on the time of data collection. Phase $\nabla$ was performed in the winter (Jan 9 to 22, 2019) and lasted 14 days. Sampling took place at Route 1 during rush-hour time periods (morning, 8:00-9:30; afternoon, 17:00-18:30) as well as at other periods (noon, 12:00-13:30; evening, 20:00-21:30). As a supplementary control trial, in order to study exposure levels under different conditions (different seasons, areas, etc.), we conducted measurements at each route during peak

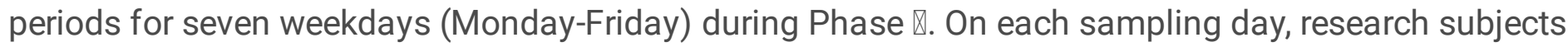
were equipped with an experimental bag packed with fundamental measuring instructions on monitoring series-related data. Due to a scarcity of instruments, measurements for the four different modes were not conducted simultaneously, but it can be assumed that successive samplings performed under the same background conditions would produce accurate results, especially if the interval between testing periods was comparatively short. $\mathrm{PM}_{1.0}, \mathrm{PM}_{2.5}$ and $\mathrm{PM}_{10}$ mass and number concentrations were collected using a portable Laser Aerosol Spectrometer and Dust Monitor (Model 11-A, GRIMM, Germany. Tolerance ranges: $\pm 3 \%$ at concentrations $\geq 500 \mathrm{~L} \mathrm{~L}^{-1}, \pm 2 \mu \mathrm{g} \cdot \mathrm{m}^{-3}$ ) based on the optical principle with a resolution of 6 seconds. The size range covered by the instrument was 0.25-32 $\mu \mathrm{m}$ over 31 channels. Subjects also wore a GPS watch (Runner 2 Cardio, Tom Tom NV, 165 Holland) to obtain the continuous data, including the HR and geographical location information, at a sampling resolution of 1 second. All volunteers were postgraduate students recruited in the Chang'an University with no health concerns or smoking habits. No sampling was conducted during days with rain, snow or heavy pollution. During the experiment periods, the ambient temperature (AT) ranged from $-7^{\circ} \mathrm{C}-30^{\circ} \mathrm{C}$ and relative humidity $(\mathrm{RH})$ ranged from $23 \%-98 \%$ from monitoring stations.

\section{Statistical analysis}

In this article, statistical software was adopted to analyze the different PM mass concentrations in different periods, among four commuting modes, and independent t-tests of different sample groups were conducted. A multivariable linear regression model and Spearman correlation analysis were applied to research the influencing factors on related pollutant levels, including background concentrations and meteorological factors (AT, RH and wind speed (WS)). The stepwise linear regression method was used to evaluate the model goodness of fit, and collinearity diagnostics were used to analyze the relevance and extent between variables, and autocorrelation (serial correlation) of the residual terms in regression analysis was checked with Durbin-Watson. The inserted experimental map was drawn with Geographic Information System software ArcGIS 10.2, and data preprocessing and final life table preparation were performed using MATLAB 2018a. All statistical significance in this study was defined as $p<0.05$ (2-tailed).

\section{Potential pollutant inhaled dose}


The quantification of inhaled or uptake dose is crucial in the analysis of the link between pollution exposure and health outcomes. Many studies have taken ventilation rate and deposition rate (DR) into consideration for obtaining more accurate results. The physiological association between HR and DR has been well documented in previous studies [29-31]. The HR data is more accessible than DR, although it is probably affected by posture, physical activity, food digestion, emotions and other ambient factors. Here the calculation method of VR presented only slight differences, as it was built by developing individual exponential regression equations [31]. Zuurbier et al. [29] found no major effects associated with age, height or body mass index, in their mixed model analysis of per-minute ventilation evaluation.) In this study, VR was defined as:

$V R=e^{a+b \times H R}$

where VR is the ventilation rate (liters per $\min , L \cdot \min ^{-1}$ ) and HR is the heart rate (beats per minute, bpm), and the default values of $a$ and $b$ were 1.17 and 0.02 for males and 0.99 and 0.02 for females, respectively.

Physical activity intensity and ventilation rate have a large effect on inhaled dose, and can reveal much about the exposure-response relationship. Calculation of potential inhaled dose of pollutants depends on the pollution concentration, exposure time and VR; the deposition rate of particulate matter was not considered here because the particle size range was too limited. The inhaled dose of pollutants ID $(\mu \mathrm{g})$ during commuting periods was calculated according to the following equation:

$$
I D=\int_{t_{1}}^{t_{2}} C_{i}(t) V R_{i}(t) d t
$$

where $\mathrm{Ci}(t)$ is the concentration measured at time $\mathrm{t}, \mu \mathrm{g} / \mathrm{m}^{3} ; \mathrm{VRi}(t)$ is the ventilation rate at time $\mathrm{t}, \mathrm{L} \cdot \mathrm{min}^{-1}$; and $t 1$ and $t 2$ are the beginning and end of the exposure episode, respectively.

In an attempt to find a formula for inhaled dose results that could be used to compare different modes and routes, and even apply to studies performed in other regions, we adopted the normalization factors shown below.

$$
\begin{aligned}
& I D_{L}=\frac{I D}{L} \\
& I D_{t}=\frac{I D}{\Delta t}
\end{aligned}
$$

\section{Years of life expectancy loss}

As the fifth-ranking mortality risk factor in 2015, ambient $\mathrm{PM}_{2.5}$ exposure caused over 4 million premature deaths worldwide [32]. There is significant evidence to prove that exposure to ambient pollution could increase morbidity and mortality and shorten life expectancy [33,34]. A link between mortality, and traffic- 
related air pollution and other traffic exposure variables, has been found over the full range of cohorts [35]. Peer-reviewed studies have also focused on pollution health effects and performed meta-analysis. Hoek et al. [36] found that the estimated pooled effect, expressed as excess risk per $10 \mu \mathrm{g} / \mathrm{m}^{3}$ increase in $\mathrm{PM}_{2.5}$ exposure concentration, was $6 \%(95 \% \mathrm{Cl} \mathrm{4,8 \% )}$ for mortality from all causes. And in dose-response functions (DRFs) for $\mathrm{PM}_{2.5}$ exposure, a relative risk value of $1.07 \mathrm{per} 10 \mu \mathrm{g} / \mathrm{m}^{3}$ increase in exposure, was adopted [37]. In order to obtain pollution data as an average per hour, a time activity pattern was assumed, for calculating a 24-h average $\mathrm{PM}_{2.5}$ concentration. The calculated specific relative risk (RR) was then combined with local demographic data and input into a life table analysis, to obtain the final YLE loss results. Since $\mathrm{PM}_{2.5}$ is the most commonly monitored pollutant, it was subsumed into the domestic ambient air quality standard for 2012. Therefore, we calculated the YLE loss based on the measured $\mathrm{PM}_{2.5}$ exposure. This approach-basing pollutant exposure on $\mathrm{PM}_{2.5}$-has been frequently used in other researches on the health effects of air pollution, providing further scientific theoretical basis for this method.

\section{Results And Discussion}

\section{Descriptive statistics}

The database of exposure during commuting was completed for the four most common public transportation modes (subway, bus, taxi and bicycle), with 224 trips in winter located at Route 1, and 112 trips in summer located at both routes. A trip was defined as travel from the origin to the destination by each specific commuting mode. Among the total experimental runs, 280 and 56 trips were monitored at Route 1 and Route 2 respectively, including 79 valid trips by subway, 80 trips by bus, 80 by taxi and 80 by bicycle, in this study (see Table 1).

Table 1. Comparison of concentrations among different modes during commuting periods

\begin{tabular}{|c|c|c|c|c|c|c|c|c|c|c|c|}
\hline \multirow{2}{*}{$\begin{array}{l}\text { Commuting } \\
\text { modes }\end{array}$} & \multirow[t]{2}{*}{ Periods } & \multirow[t]{2}{*}{$\mathrm{N}^{*}$} & \multicolumn{3}{|c|}{$\mathrm{PM}_{10} * *\left(\mu \mathrm{g} / \mathrm{m}^{3}\right)$} & \multicolumn{3}{|c|}{$\mathrm{PM}_{2.5}\left(\mu \mathrm{g} / \mathrm{m}^{3}\right)$} & \multicolumn{3}{|c|}{$\mathrm{PM}_{1.0}\left(\mu \mathrm{g} / \mathrm{m}^{3}\right)$} \\
\hline & & & Mean & SD & Range & Mean & $\mathrm{SD}$ & Range & Mean & SD & Range \\
\hline \multirow[t]{4}{*}{ Subway } & Morning & 26 & 74.19 & 32.84 & $38.22-182.99$ & 53.17 & 32.49 & $19.77-158.82$ & 43.06 & 31.04 & $12.84-140.75$ \\
\hline & Noon & 13 & 77.91 & 37.41 & $40.68-137.70$ & 62.01 & 35.12 & $19.84-118.11$ & 53.93 & 32.88 & 12.39-107.01 \\
\hline & Afternoon & 27 & 59.08 & 30.26 & 27.36-137.96 & 43.52 & 25.71 & 20.06102 .73 & 36.41 & 23.43 & $14.07-90.77$ \\
\hline & Evening & 13 & 84.39 & 35.57 & $40.09-149.23$ & 64.20 & 32.99 & $29.98-122.86$ & 53.94 & 30.52 & $20.79-108.83$ \\
\hline \multirow[t]{4}{*}{ Bus } & Morning & 27 & 125.84 & 49.71 & $21.16-233.70$ & 71.34 & 45.93 & $17.01-175.86$ & 53.67 & 41.47 & 7.78-145.04 \\
\hline & Noon & 13 & 132.68 & 52.33 & $66.14-206.24$ & 82.89 & 49.22 & $16.67-149.84$ & 65.47 & 44.19 & $6.74-125.19$ \\
\hline & Afternoon & 27 & 102.47 & 56.50 & $21.16-206.17$ & 54.86 & 38.62 & $17.01-143.35$ & 40.43 & 32.78 & $10.94-117.83$ \\
\hline & Evening & 13 & 127.92 & 47.58 & 65.99-215.29 & 77.03 & 44.79 & $22.44-164.40$ & 60.14 & 40.65 & $12.92-138.14$ \\
\hline \multirow[t]{4}{*}{ Taxi } & Morning & 27 & 119.80 & 57.10 & $34.88-273.60$ & 65.22 & 38.82 & 13.69-183.59 & 47.71 & 35.60 & $5.05-160.63$ \\
\hline & Noon & 13 & 97.66 & 43.28 & $32.87-190.20$ & 66.04 & 37.96 & $12.05-147.31$ & 53.55 & 35.33 & $4.79-124.97$ \\
\hline & Afternoon & 27 & 90.40 & 48.76 & $19.09-160.17$ & 51.12 & 34.15 & $10.40-119.01$ & 39.41 & 30.76 & 8.60-103.29 \\
\hline & Evening & 13 & 106.65 & 39.15 & $41.55-160.97$ & 72.89 & 40.23 & $16.61-134.62$ & 59.48 & 37.18 & $9.68-118.35$ \\
\hline \multirow[t]{4}{*}{ Bicycle } & Morning & 27 & 115.42 & 50.92 & $43.67-256.44$ & 71.91 & 50.71 & $23.02-208.45$ & 55.13 & 44.76 & 7.28-178.36 \\
\hline & Noon & 13 & 138.50 & 81.21 & $55.61-300.17$ & 86.10 & 54.57 & $17.01-176.33$ & 69.88 & 48.53 & $8.44-152.02$ \\
\hline & Afternoon & 27 & 98.52 & 42.99 & $43.35-185.42$ & 58.54 & 37.51 & $20.85-141.52$ & 44.22 & 33.62 & $12.36-120.83$ \\
\hline & Evening & 13 & 135.03 & 50.71 & $65.22-220.63$ & 84.50 & 51.91 & $27.23-185.00$ & 68.00 & 47.26 & 15.93-159.90 \\
\hline
\end{tabular}


The statistical data presented in Table 1 is composed of concentrations inside vehicles, and on platforms or at stations. The duration of sampling depended on the particular situation. Since subway trains travel a controlled distance, commuting exposure times for this mode were comparatively stable, but this was not true for other modes, where travel times could fluctuate depending on the specific traffic characteristics (congestion, signals, etc.). As can be seen from Table 1, the overall average concentration of $\mathrm{PM}_{10}$ ranged from 19.09 to $300.17 \mu \mathrm{g} / \mathrm{m}^{3}$, and average concentrations for specific modes were 74.19 , $125.84,119.80,115.42 \mu \mathrm{g} / \mathrm{m}^{3}$ for subway, bus, taxi and bicycle respectively. The overall average concentration of $\mathrm{PM}_{2.5}$ varied from 10.40 to $208.45 \mu \mathrm{g} / \mathrm{m}^{3}$, and for more than half the trips the exposure level was never lower than double the WHO guideline value for 24-h average $\mathrm{PM}_{2.5}$ concentration $\left(25 \mu \mathrm{g} / \mathrm{m}^{3}\right)$. In general, PM pollution levels were higher in bus and bicycle trips compared to subway and taxi, although these values differ from those found in other literatures published in other regions, due to trial discrepancies. Strasser et al. [38] observed that mean PM mass concentrations were higher in subways than in buses or cars using low-ventilation settings, and the highest PM concentrations were found in active modalities like walking and cycling: approximately 2, 4 and 3 times higher for $\mathrm{PM}_{10}, \mathrm{PM}_{2.5}$ and $\mathrm{PM}_{1.0}$ respectively, than in cars [39]. During rush hours, the measured concentrations were higher in the morning than in the afternoon, with no obvious regularities in non-peak periods. This was true for all commuting modes.

\section{Concentration variations}

\section{Subway}

As the most important mode in commuter traffic, the subway played a key role in relieving traffic congestion, due to its large transportation capacity. Advantages such as punctuality and comfort have made it more popular in recent years. Although electric-powered trains have no exhaust emissions, pollution penetrates from external surroundings and accumulates in the relatively closed station areas, potentially damaging the health of passengers crowded into the interior-a situation that has drawn researchers' attention. In the literature, the total average pollutant concentrations in subway trains were found to be $71.32,53.14$ and $44.37 \mu \mathrm{g} / \mathrm{m}^{3}$ for $\mathrm{PM}_{10}, \mathrm{PM}_{2.5}$ and $\mathrm{PM}_{1.0}$, respectively. Average $\mathrm{PM}_{2.5}$ concentrations in the carriages and on the subway platforms during operating hours ranged from 16.05 to 122.47 and from 22.46 to $202.45 \mu \mathrm{g} / \mathrm{m}^{3}$, respectively. Similar discrepancies were also found in Martins et al. [40] (carriage: 20-51, platform: 41-91 $\mu \mathrm{g} / \mathrm{m}^{3}$ ) and Qiu et al. [20] (carriage: 13.3-134.7, platform: 35.6$140.9 \mu \mathrm{g} / \mathrm{m}^{3}$ ). Particulate matter levels in vehicle cabins are always lower than the background concentrations in winter, and the converse in summer, when the background concentrations are comparatively lower. For example, for $\mathrm{PM}_{2.5}$ the average ratio of in-cabin/background is 0.55 (range: 0.31-0.97, SD: 0.162); for in-cabin/on-station, 0.74 (range: 0.48-1.13, SD: 0.129) for all trips. Some 
possible reasons include: sealed spaces can be protected from severe ambient pollution by shields, and installed air purification devices could filter out a portion of the pollution; but when the background concentration is comparatively lower, the proportion of in-vehicle pollution would rise. In-vehicle pollution in the subway station includes mechanical abrasion between rails, wheels, and brakes of trains, and tiny dust driven by the motion of trains through tunnels [41-43].

\section{Bus}

Buses, one of the traditional common traffic modes, have become more popular as a way of mitigating traffic congestion. According to the Xi'an Transportation Development Annual Report 2018, 307 bus routes were running within the city, and had carried 1.359 billion passengers that year, accounting for $55.1 \%$ of public transportation passenger volume. The literature has shown that bus travelers suffer the highest PM exposure $\left(\mathrm{PM}_{10}: 116.29 \mu \mathrm{g} / \mathrm{m}^{3}, \mathrm{PM}_{2.5}: 67.60 \mu \mathrm{g} / \mathrm{m}^{3}, \mathrm{PM}_{1.0}: 51.12 \mu \mathrm{g} / \mathrm{m}^{3}\right)$ of all the studied motorized modes. Bus-station and in-cabin levels were similar (the average ratio of station/in-cabin levels was $0.96(0.63-1.43)$ ), possibly because frequent boarding and disembarking, and open windows, enhance the air exchange between the interior and the outside environment. Fig. 2 (c) shows the monitored PM concentrations in different seasons, demonstrating that PM pollution levels were higher in winter compared to summer. Differences in $\mathrm{PM}_{10}$ mass concentrations were found for two fixed routes, where buses were powered by different energy sources (Fig. 2 (d)). Although experimental analysis revealed that the in-cabin $\mathrm{PM}_{1.0}$ mass concentrations inside electric buses were close to those of CNG buses, with no controlling variables, vehicle fuels still could be one of the influencing factors for emission

exposure. Vijayan and Kumar [44] found that in-vehicle $\mathrm{PM}_{1.0}$ levels were lower when buses were powered by biodiesel rather than with traditional diesel fuel. PM levels in bus cabins were also were affected by other factors; Targino et al. [45] suggested that traffic volume on the roads the buses were traveling on, the number of stops the buses made, and displacement speed, were the main determinants of air pollution on a bus.

\section{Taxi}

Taxis have recently taken on a considerable share of the transport market in China, because of their comfort, convenience and flexibility. Previous studies have focused on the safety records of taxi drivers [46-48], and on atmospheric pollutants in taxi cabins. For the taxi, just as for the private car, ventilation settings have been shown to have a significant impact on in-vehicle mass and number concentrations $[39,49]$. Taxis, however, have shorter life spans and operate under worse road conditions than private cars. Fig. 2 (e) reveals that commuters riding in taxis in winter experienced higher pollution exposure than in summer, probably because of the higher background concentration in the cities in northern regions, where cabin heating systems are likely to be more heavily used. In an effort to shift to less polluting energy sources, methanol taxis have recently been launched in Xi'an. We collected in-cabin pollution data from three taxis, powered by different fuels; the results are shown in Fig. 2 (f). PM levels in taxi cabins were higher when the engine was powered by traditional gasoline as compared to compressed natural gas (CNG) or methanol. Transitioning taxi fuel type from gasoline to CNG could reduce in-cabin $\mathrm{PM}_{2.5}$ 
concentrations by up to $56.2 \%$; to methanol, up to $83.8 \%$. There is no doubt that popularizing cleaner fuels (compressed natural gas or methanol) could decrease PM emissions and commuters' exposure levels. Despite this evidence, though, "traditional" fossil fuels are still being increasingly consumed, largely because of the governmental policy that civilian use of the CNG supply in winter could aggravate the air pollution damage to public health.

\section{Bicycle}

Cycling has become more popular, probably because of the increased accessibility of publicly shared bicycles in China. Fierce competition between bike-sharing vendors has promoted the popularization of bicycles, which have now become an indispensable part of daily life, especially as a link to other modes of transportation, solving the "last-mile" problem. As a zero-emissions active commuting mode, bicycling is beneficial in several ways: it lowers traffic emissions, eases traffic congestion, and helps improve both physical and mental health. However, despite these widely touted positive benefits, cycling may be linked to exposure to air pollution and road traffic noise [23,50], and thereby cause adverse health outcomes. Taking into account the increased breathing rates required to sustain the higher level of physical activity, cyclists are generally exposed to the most severe pollution, among all the various modes of transportation [51,52]. Similarly, the measured PM mass concentrations during cycling trips were higher in winter months than in summer, and discrepancy between R1 and R2 was found in the average $\mathrm{PM}_{10}$ mass concentrations (Fig. 2), likely because of the presence of more heavy-duty trucks recorded at R2 during the sampling time.

\section{Influencing factors on exposure concentrations}

It is increasingly crucial to determine the factors that influence public commuting exposure to trafficrelated air pollution to reference these factors when planning urban construction projects and protecting public health. Table S1 shows the Spearman correlation coefficients between commuting pollution levels, and background pollution values and meteorological factors. The $\mathrm{PM}_{10}$ mass concentration was significantly related to the $\mathrm{PM}_{2.5}(0.825-0.948, \mathrm{p}<0.01)$ and $\mathrm{PM}_{1.0}(0.644-0.899, \mathrm{p}<0.01)$ levels, and $(0.948$ $0.986, \mathrm{p}<0.01$ ) between $\mathrm{PM}_{2.5}$ and $\mathrm{PM}_{1.0}$, and a similar conclusion has been obtained in previous studies [20]. Background pollution concentration monitored at fixed stations was chosen to represent the local air-pollution level, but is not accurate for commuting periods. The correlations between both $\mathrm{PM}_{10}$ and $\mathrm{PM}_{2.5}$ and background values ranged from 0.746 to 0.952 , except for taxi trips. The time series plots of average pollution levels of sampling trips and corresponding background concentrations are shown in Fig. S1. We found that the background pollution we monitored was more severe than that during commuting periods for samplings conducted in winter, and found converse results for summer. In the winter, traffic-related air pollution was not the only pollution source in the sampling areas; building heating also contributed to pollution levels.

Being adjacent to pollution sources and hence directly exposed to more severe traffic pollution, both cyclists and bus commuters experienced higher risk. Rivas et al. [53] found that commuters come in 
contact with highly variable concentrations of atmospheric pollutants and face short-term extreme peak concentrations that result in significant contributions (12-32\%) to their total daily exposure.

Meteorological conditions also play an important role in the diffusion, dilution, condensation/evaporation, coagulation, and deposition of particulate matter. Several studies have indicated that meteorological factors had a significant effect on commuters' exposure. It has been shown that ambient temperature and relative humidity have a moderate association with $\mathrm{PM}\left(\mathrm{PM}_{10}, \mathrm{PM}_{2.5}\right.$ and $\mathrm{PM}_{1.0}$ ) mass concentrations, and there is weak evidence of an association between PM mass concentration and wind speed.

Taking $\mathrm{PM}_{10}$ as an example, analysis results of a multivariable linear regression model are shown in Table 2. Obvious variance was found in the $\mathrm{PM}_{10}$ models, among the different commuting modes. The 87.8 (adjusted $\mathrm{R}^{2}$ ) of measured $\mathrm{PM}_{10}$ aberrance can be explained in the $\mathrm{PM}_{10}$ model, and the outcomes revealed that BPC $\left(\beta_{1}=0.845, p<0.001\right), R H\left(\beta_{2}=0.197 \rrbracket p<0.001\right)$ and $W S\left(\beta_{3}=0.084, p=0.045\right)$ were significant influencing factors on $\mathrm{PM}_{10}$ exposure in subways. Similarly, we found that the $65.8 \%$ and $71.6 \%$ (adjusted $\mathrm{R}^{2}$ ) of observed $\mathrm{PM}_{10}$ aberrance can be explained by the $\mathrm{PM}_{10}$ models for bus and bicycle, respectively; both $B P C$ and atmospheric factors (AT and $\mathrm{RH})$ were main determinants of $\mathrm{PM}_{10}$ exposure. The $\mathrm{PM}_{10}$ model for taxis suggested that the $\mathrm{RH}\left(\beta_{1}=0.504, \mathrm{p}<0.001\right)$ had more effect on the $\mathrm{PM}_{10}$ monitored in taxi cabins, possibly because of individual habits of ventilation mode use and of driving behaviors. The multiple types of taxis utilized in our study could also be one of reasons for these variations. Further researches are needed, to explore the more decisive determinants on PM exposure in taxi cabins. We found that BPC was the dominant factor influencing commuters' exposure levels, but was not applicable to all cases. Furthermore, when BPCs were comparatively low, exposure levels were mainly affected by other factors (like self-pollution, including abrasion of auto parts, ground or traces) (see Fig. 3). Thus "proper" choice of commuting mode could effectively avoid high pollution exposure: PM levels were apparently lower in subways and taxis, compared to bus and cycling (Fig. 3(a). Bus and subway commuters' exposure to higher PM levels during waiting periods (by means of vehicle real-time location software) could lower exposure by reducing wait time. In Fig. 3(b), the "hotspots" could be caused by special circumstances like congestion or temporary construction.

Table 2. Parameters in the multivariable linear regression models for $\mathrm{PM}_{10}$ exposure 


\begin{tabular}{lllll}
\hline Independent variables & \multicolumn{2}{l}{ Model Coefficients } & Sig. \\
& $\beta$ & $95 \% \mathrm{CI}$ & $\beta^{*}$ & \\
\hline Subway & & & & \\
$\mathrm{PM}_{10}$ model (adjusted $\left.\mathrm{R}^{2}=0.878\right)$ & & & $\mathrm{P}<0.001$ \\
Constant & 14.02 & $(5.82-222.22)$ & & $\mathrm{P}=0.001$ \\
$\mathrm{BPC}\left(\mu \mathrm{g} / \mathrm{m}^{3}\right)$ & 0.278 & $(0.250-0.306)$ & 0.845 & $\mathrm{P}<0.001$ \\
$\mathrm{RH}(\%)$ & 22.56 & $(12.27-32.86)$ & 0.187 & $\mathrm{P}<0.001$ \\
WS $(\mathrm{level})$ & -3.82 & $(-7.55--0.09)$ & -0.084 & $\mathrm{P}=0.045$ \\
\hline Bus & & & & \\
$\mathrm{PM}{ }_{10}$ model (adjusted $\left.\mathrm{R}^{2}=0.658\right)$ & & & & $\mathrm{P}<0.001$ \\
Constant & 41.59 & $(19.77-63.42)$ & & $\mathrm{P}<0.001$ \\
$\mathrm{BPC}\left(\mu \mathrm{g} / \mathrm{m}^{3}\right)$ & 0.370 & $(0.255-0.486)$ & 0.561 & $\mathrm{P}<0.001$ \\
$\mathrm{AT}\left({ }^{\circ} \mathrm{C}\right)$ & -1.17 & $(-1.98--0.354)$ & -0.242 & $\mathrm{P}=0.006$ \\
$\mathrm{RH}(\%)$ & 70.86 & $(33.35-108.38)$ & 0.293 & $\mathrm{P}<0.001$ \\
\hline Taxi & & & & \\
$\mathrm{PM}{ }_{10}$ model (adjusted $\left.\mathrm{R}^{2}=0.244\right)$ & & & & $\mathrm{P}<0.001$ \\
Constant & 17.16 & $(-16.31-50.64)$ & & $\mathrm{P}=0.310$ \\
$\mathrm{RH}(\%)$ & 132.63 & $(80.33-184.94)$ & 0.504 & $\mathrm{P}<0.001$ \\
\hline Bicycle & & & & \\
$\mathrm{PM}{ }_{10}$ model (adjusted $\left.\mathrm{R}^{2}=0.716\right)$ & & & & $\mathrm{P}<0.001$ \\
$\mathrm{Constant}$ & 30.13 & $(9.18-50.07)$ & & $\mathrm{P}=0.005$ \\
$\mathrm{BPC}\left(\mu \mathrm{m} / \mathrm{m}^{3}\right)$ & 0.423 & $(0.312-0.534)$ & 0.612 & $\mathrm{P}<0.001$ \\
$\mathrm{AT}\left({ }^{\circ} \mathrm{C}\right)$ & -1.08 & $(-1.87--0.295)$ & -0.213 & $\mathrm{P}=0.008$ \\
$\mathrm{RH}(\%)$ & 74.62 & $(38.51-110.73)$ & 0.294 & $\mathrm{P}<0.001$ \\
\hline
\end{tabular}

$\beta$ non-standardized coefficients; $\beta^{*}$ standardized coefficients

A spatial distribution of $\mathrm{PM}_{2.5}$ mass concentration for different modes is shown in Fig. 4. During this sampling, the lowest pollution concentrations were found in the taxi commuting trips, for vehicles operating in air-conditioning mode and powered by methanol. Higher pollution levels were found at the beginning of a taxi trip, but dropped steadily until arrival at the destination; this pattern might be attributed to the ventilation mode. This was followed by the subway, in which several "red" hotspots were detected near the subway stations where there were short delays; these were likely caused by air exchange during the boarding/disembarking time. The pollution level dropped during the traveling periods, due to the activation of purification devices. Next was the bus trip, where frequent boarding and traffic congestion brought severe in-cabin air pollution during most of the commuting time. Cyclists experienced the most severe pollution among the four common traffic modes, and higher exposure concentrations were found when they crossed the "street canyons" identified in the satellite remote sensing map. (Several related studies have stressed the importance of land-use types on pollution diffusion [54]).

\section{Potential inhaled dose}

Ventilation rates have a bearing on an individual's dose and are crucial to consider in exposure-respond relationships. A method of using heart rate to indirectly calculate ventilation rate was adopted, and the results are shown in Table 3. In this study, 13 volunteers (the sex ratio was close to 0.5 ) were employed to collect heart rate data before the experiments, and all participants were in good health and were nonsmokers. We found an obvious and expected sexual discrepancy in VR (higher in females than in males), mainly due to the more massive body and larger lung capacity of males. Bicycle riding is a moderate activity, and the VR during cycling is highest compared to the other modes, which were defined as light 
activity. The average VR is close to $23.5 \mathrm{~L} / \mathrm{min}$ (published in Zuurbier et al. [29]) for bicycling commuters, but no higher than $11.8 \mathrm{~L} / \mathrm{min}$ for passengers in vehicles.

The inhaled dose results for the four commuting modes were the products of exposure concentration, commuting time and ventilation rates, as shown in Table 4. Cyclists experienced the greatest trafficrelated pollution exposure relative to the other modes. In contrast, comparatively lower pollutant concentration levels and shorter exposure duration meant lower inhaled doses for subway riders $(5.00 \mu \mathrm{g})$, indicating that choosing the most suitable commuting mode is an important mitigation measure for the traveling public. While exposure per unit distance $\left(D_{L}\right)$ or time $\left(D_{t}\right)$ may not represent the total actual health risk, it can provide a general comparison for different modes, and correlates well with conclusions from other literature. Moreover, it can be computed based on internet data and applied extensively in mapping applications, so that residents could select their best commuting option. The lowest average exposure for both $D_{L}$ and $D_{t}$ was found for the subway, with $1.47 \mu \mathrm{g} / \mathrm{km}, 0.88 \mu \mathrm{g} / \mathrm{min}$, compared to the highest-for cycling ( $\left.D_{\mathrm{L}}: 8.37 \mu \mathrm{g} / \mathrm{km}, D_{t}: 1.82 \mu \mathrm{g} / \mathrm{min}\right)$. In terms of pollution exposure, substituting the subway for cycling could mitigate the most adverse effects of exposure, although the low cost and health benefits of cycling should not be overlooked.

Table 3. Summary of measured heart rates and calculated ventilation rates

\begin{tabular}{cccccc}
\hline & \multirow{2}{*}{$\mathrm{N}$} & \multicolumn{2}{c}{ HR $(\mathrm{bpm})$} & \multicolumn{2}{c}{ VR $((\mathrm{L} / \mathrm{min})$} \\
\cline { 3 - 6 } & & Male & Female & Male & Female \\
\hline Subway & 13 & 91 & 94 & 19.89 & 21.12 \\
Bus & 13 & 83 & 84 & 16.95 & 17.29 \\
Taxi & 13 & 81 & 85 & 16.28 & 17.64 \\
Bicycle & 13 & 101 & 112 & 24.29 & 30.27 \\
\hline
\end{tabular}

Table 4. Potential inhaled dose and unit normalization results

\begin{tabular}{cccccccc}
\hline & $\mathrm{N}$ & Commuting duration (min) & $\mathrm{VR}(\mathrm{L} / \mathrm{min})$ & $\mathrm{C}\left(\mu \mathrm{g} / \mathrm{m}^{3}\right)$ & Inhale dose $(\mu \mathrm{g})$ & $\mathrm{D}_{\mathrm{L}}(\mu \mathrm{g} / \mathrm{km})$ & $\mathrm{D}_{\mathrm{t}}(\mu \mathrm{g} / \mathrm{min})$ \\
\hline Subway & 79 & 5.7 & 19.0 & 46.20 & 5.00 & 1.47 & 0.88 \\
Bus & 80 & 10.4 & 15.9 & 67.60 & 11.18 & 3.29 & 1.07 \\
Taxi & 80 & 9.8 & 15.7 & 58.77 & 9.04 & 2.66 & 0.92 \\
Bicycle & 80 & 15.6 & 25.2 & 72.37 & 28.45 & 8.37 & 1.82 \\
\hline
\end{tabular}

\section{Estimation of YLE loss}

Epidemiological and clinical studies have revealed that long-term air pollution exposure is associated with increased incidence of various diseases and consequent morbidity risk, and even mortality rate [5557]. Mortality, as an indicator reflecting the health status of residents and a measure of the degree of damage to life, is widely used in health impact assessments [58,59]. But mortality treats each age group equally, and cannot show the difference in loss of life for different age groups; the YLE loss compensates for this deficiency. Wang et al. [60] concluded, by collecting and calculating $\mathrm{PM}_{10}$ pollution data for 20032010 , that domestic air quality has a significant impact on residents' life expectancy. And a time series 
study conducted in Wuxi evaluated air pollution-related mortality and life loss by applying the linear and Poisson regression models [61].

Barely any studies have focused on the life loss caused by air pollution in transportation microenvironments. Based on the 2010 Population Census of the People's Republic of China, the average YLE of the urban population is 82.17 years. For people who travel primarily by subway, we estimated the lowest average YLE loss was 0.64 (0.49-0.71) months. Because of the independent operating space and advanced air purification systems, subway commuters would suffer only slight harm, while the commuting mode with the highest exposure concentration and consequent greatest YLE loss was found to be cycling (5.78 (4.39-6.43) months). But this conclusion does not mean that cycling is undesirable. De Hartog et al. [62] observed that the benefits from physical activities like cycling outweigh the life loss caused by air pollution and crashes, when large numbers of people make the car-bicycle shift, especially as increased numbers of bikers could diminish the frequency of motor vehicle use and cut down on traffic exhaust emissions. Johansson et al. [63] suggested that the potential of transitioning from private car use to bicycling is great, and the resulting drop in air pollution could save 449 years annually for 2.1 million urban inhabitants if 111,000 commuters made the switch. Besides, the YLE losses for residents who take buses or taxis were 3.36 (2.56-3.74) months, 2.32 (1.77-2.57) months respectively.

The YLE loss for people in different life stages (age above 15 years old) was studied, and the results are shown in Fig. 5. We observed a large heterogeneity among distinct age groups. Young commuters (15-39 years of age) experienced greater life loss than those among 40-64 years of age, and the YLE loss of older persons (age $\geq 65$ years) was lowest, most likely because younger people have longer YLE (more potential years ahead of them) and hence more years of air pollution inhalation, and because senior citizens presumably travel less.

\section{Conclusions}

In this study, we conducted mobile measuring experiments along two different roads, and collected PM pollution data on 319 valid trips among four public transportation modes (subway, bus, taxi and bicycle) in winter and summer. Analysis results showed that there exists significant heterogeneity in commuting exposure to pollution, among these different traveling modes.

Cyclists suffered the most severe overall PM exposure, while subway commuters suffered the lowest $\mathrm{PM}_{2.5}$ exposure concentration levels. The exposure levels inside stations and vehicle cabins were monitored for all applicable modes (i.e., not including cycling), and we observed that the highest concentrations were measured at stations. Because they travel adjacent to motorized lanes, close to emission sources, and have the highest respiration rates, cyclists are at the most risk while riding, from air pollution-even more than from crashes or during the time they spend searching for cycles from bikesharing lots or preparing for their rides. 
The average PM concentrations were higher in winter than in summer, in this study. Background pollution levels had a great effect on measured values during commuting periods, and on days when the air quality was ranked 'good' or 'excellent,' lower commuting PM concentrations were found. Analysis of daily timeseries concentrations revealed that the evening commuting period (20:00-21:30) presented the highest PM levels for all modes except taxi, which had lower levels then, than in the morning commuting period. It was also confirmed that meteorological factors are associated with PM mass concentration levels.

Fuel types influenced in-cabin PM concentrations during taxi trips (a shift from gasoline to CNG or methanol could cut down $56.2 \%$ or $83.8 \%$ of $\mathrm{PM}_{2.5}$ mass concentrations), and electric buses were observed to have even lower PM concentrations than those powered by CNG. These results illustrate that optimizing energy structure policies, such as the launch of more methanol-powered and electric vehicles, could effectively reduce exhaust emissions and commuters' exposure levels.

Urban inhabitants' YLE loss in this study was obtained based on the average $\mathrm{PM}_{2.5}$ mass concentration, and was calculated as $0.64,3.36,2.31$ and 5.78 months for subway, bus, taxi and bicycle, respectively. Further research could focus on pollutants that have been found to have even greater toxicity, such as black carbon or ultrafine particulates. Acquisition of larger samples and combining the results with local medical department data could effectively improve the accuracy of the final results. Long-term mobile monitoring campaigns could, furthermore, provide massive practical data support for related studies on transportation and the environment.

\section{Abbreviations}

TRAP: Traffic-related air pollution; PM: Particulate matter; YLE: Years of life expectancy; CNG:

Compressed natural gas; AQI: Air quality index; VR: Ventilation rate; HR: Heart rate; LDSA: Lung deposited surface area; AT: Ambient temperature; RH: Relative humidity; WS: Wind speed; DR: Deposited rate; DRFs: Dose-response functions; BPC: Background pollutants concentration

\section{Declarations}

\section{Acknowledgements}

We acknowledge volunteers for providing cooperation and assistance in the sampling experiments.

\section{Authors' contributions}

Zheng $\mathrm{J}$ participated in the conceive and design of this study, and contributed to data acquisition and processing. Qiu Z participated in the conceive and design of the study. Both of authors contributed to drafting the manuscript and reviewed and approved the final version.

\section{Funding}


This study was supported by the Natural Science Basic Research Plan in Shaanxi Province of China (Program No. 2020JM-225) and the Scientific Innovation Practice Project of Postgraduates of Chang'an University.

\section{Availability of data and materials}

The datasets used and/or analyzed during the current study are available from the corresponding author on reasonable request.

\section{Ethics approval and consent to participate}

Not applicable

\section{Consent for publication}

Not applicable

\section{Competing interests}

Not applicable

\section{References}

1. Künzli N, Kaiser R, Medina S, Studnicka M, Chanel O, Filliger P, et al. Public-health impact of outdoor and traffic-related air pollution: a European assessment. Lancet [Internet]. 2000;356:795-801. Available from: https://linkinghub.elsevier.com/retrieve/pii/S0140673600026532

2. Gehring U, Cyrys J, Sedlmeir G, Brunekreef B, Bellander T, Fischer P, et al. Traffic-related air pollution and respiratory health during the first 2 yrs of life. Eur. Respir. J. 2002;19:690-8.

3. Wellenius GA, Bateson TF, Mittleman MA, Schwartz J. Particulate Air Pollution and the Rate of Hospitalization for Congestive Heart Failure among Medicare Beneficiaries in Pittsburgh, Pennsylvania. Am J Epidemiol [Internet]. 2005;161:1030-6. Available from: http://academic.oup.com/aje/article/161/11/1030/115578/Particulate-Air-Pollution-and-the-Rate-of

4. Hampel R, Peters A, Beelen R, Brunekreef B, Cyrys J, de Faire U, et al. Long-term effects of elemental composition of particulate matter on inflammatory blood markers in European cohorts. Environ Int [Internet]. 2015;82:76-84. Available from:

https://linkinghub.elsevier.com/retrieve/pii/S0160412015001233

5. Boggia B, Carbone U, Farinaro E, Zarrilli S, Lombardi G, Colao A, et al. Effects of working posture and exposure to traffic pollutants on sperm quality. J Endocrinol Invest [Internet]. 2009;32:430-4. Available from: http://link.springer.com/10.1007/BF03346481

6. Brauer M, Lencar C, Tamburic L, Koehoorn M, Demers P, Karr C. A Cohort Study of Traffic-Related Air Pollution Impacts on Birth Outcomes. Environ Health Perspect [Internet]. 2008;116:680-6. Available from: https://ehp.niehs.nih.gov/doi/10.1289/ehp.10952 
7. Grana M, Toschi N, Vicentini L, Pietroiusti A, Magrini A. Exposure to ultrafine particles in different transport modes in the city of Rome. Environ Pollut [Internet]. 2017;228:201-10. Available from: https://linkinghub.elsevier.com/retrieve/pii/S0269749116316335

8. Ranft U, Schikowski T, Sugiri D, Krutmann J, Krämer U. Long-term exposure to traffic-related particulate matter impairs cognitive function in the elderly. Environ Res. 2009;109:1004-11.

9. Tan C, Wang Y, Lin M, Wang Z, He L, Li Z, et al. Long-term high air pollution exposure induced metabolic adaptations in traffic policemen. Environ Toxicol Pharmacol. 2018;58:156-62.

10. Zhu J, Lee RW, Twum C, Wei Y. Exposure to ambient PM 2.5 during pregnancy and preterm birth in metropolitan areas of the state of Georgia. Environmental Science and Pollution Research; 2019;26:2492-500.

11. Huang J, Deng F, Wu S, Guo X. Comparisons of personal exposure to PM2.5 and CO by different commuting modes in Beijing, China. Sci Total Environ [Internet]. 2012;425:52-9. Available from: https://linkinghub.elsevier.com/retrieve/pii/S0048969712003397

12. Ham W, Vijayan A, Schulte N, Herner JD. Commuter exposure to PM2.5, BC, and UFP in six common transport microenvironments in Sacramento, California. Atmos Environ [Internet]. 2017;167:335-45. Available from: https://linkinghub.elsevier.com/retrieve/pii/S1352231017305290

13. Hankey S, Marshall JD. On-bicycle exposure to particulate air pollution: Particle number, black carbon, PM2.5, and particle size. Atmos Environ [Internet]. Elsevier Ltd; 2015;122:65-73. Available from: http://dx.doi.org/10.1016/j.atmosenv.2015.09.025

14. Shen J, Gao Z. Commuter exposure to particulate matters in four common transportation modes in Nanjing. Build Environ [Internet]. 2019;156:156-70. Available from:

https://linkinghub.elsevier.com/retrieve/pii/S0360132319302628

15. Tsai D-H, Wu Y-H, Chan C-C. Comparisons of commuter's exposure to particulate matters while using different transportation modes. Sci Total Environ [Internet]. 2008;405:71-7. Available from: https://linkinghub.elsevier.com/retrieve/pii/S0048969708006736

16. Apte JS, Kirchstetter TW, Reich AH, Deshpande SJ, Kaushik G, Chel A, et al. Concentrations of fine, ultrafine, and black carbon particles in auto-rickshaws in New Delhi, India. Atmos Environ [Internet]. 2011;45:4470-80. Available from: https://linkinghub.elsevier.com/retrieve/pii/S1352231011005206

17. Mazaheri M, Clifford S, Yeganeh B, Viana M, Rizza V, Flament R, et al. Investigations into factors affecting personal exposure to particles in urban microenvironments using low-cost sensors. Environ Int [Internet]. 2018;120:496-504. Available from: https://linkinghub.elsevier.com/retrieve/pii/S0160412018301934

18. Peters J, Van den Bossche J, Reggente M, Van Poppel M, De Baets B, Theunis J. Cyclist exposure to UFP and BC on urban routes in Antwerp, Belgium. Atmos Environ [Internet]. Elsevier Ltd; 2014;92:3143. Available from: http://dx.doi.org/10.1016/j.atmosenv.2014.03.039

19. Qiu Z, Wang W, Zheng J, Lv H. Exposure assessment of cyclists to UFP and PM on urban routes in Xi'an, China. Environ Pollut [Internet]. Elsevier Ltd; 2019;250:241-50. Available from: https://doi.org/10.1016/j.envpol.2019.03.129 
20. Qiu Z, Song J, Xu X, Luo Y, Zhao R, Zhou W, et al. Commuter exposure to particulate matter for different transportation modes in Xi'an, China. Atmos Pollut Res [Internet]. 2017;8:940-8. Available from: https://linkinghub.elsevier.com/retrieve/pii/S1309104216305402

21. Liu W-T, Ma C-M, Liu I-J, Han B-C, Chuang H-C, Chuang K-J. Effects of commuting mode on air pollution exposure and cardiovascular health among young adults in Taipei, Taiwan. Int $\mathrm{J}$ Hyg Environ Health [Internet]. 2015;218:319-23. Available from: https://linkinghub.elsevier.com/retrieve/pii/S143846391500005X

22. Morales Betancourt R, Galvis B, Balachandran S, Ramos-Bonilla JP, Sarmiento OL, Gallo-Murcia SM, et al. Exposure to fine particulate, black carbon, and particle number concentration in transportation microenvironments. Atmos Environ [Internet]. 2017;157:135-45. Available from: https://linkinghub.elsevier.com/retrieve/pii/S1352231017301309

23. Apparicio P, Carrier M, Gelb J, Séguin AM, Kingham S. Cyclists' exposure to air pollution and road traffic noise in central city neighbourhoods of Montreal. J Transp Geogr [Internet]. The Authors; 2016;57:63-9. Available from: http://dx.doi.org/10.1016/j.jtrangeo.2016.09.014

24. Giménez-Gaydou DA, Cupido dos Santos A, Mendes G, Frade I, Ribeiro ASN. Energy consumption and pollutant exposure estimation for cyclist routes in urban areas. Transp Res Part D Transp Environ [Internet]. Elsevier; 2019;72:1-16. Available from: https://doi.org/10.1016/j.trd.2019.04.005

25. Goel R, Gani S, Guttikunda SK, Wilson D, Tiwari G. On-road PM2.5 pollution exposure in multiple transport microenvironments in Delhi. Atmos Environ [Internet]. 2015;123:129-38. Available from: https://linkinghub.elsevier.com/retrieve/pii/S1352231015304556

26. Yang F, Kaul D, Wong KC, Westerdahl D, Sun L, Ho K, et al. Heterogeneity of passenger exposure to air pollutants in public transport microenvironments. Atmos Environ [Internet]. 2015;109:42-51. Available from: https://linkinghub.elsevier.com/retrieve/pii/S135223101500223X

27. Geiss O, Bianchi I, Barrero-Moreno J. Lung-deposited surface area concentration measurements in selected occupational and non-occupational environments. J Aerosol Sci [Internet]. Elsevier; 2016;96:24-37. Available from: http://dx.doi.org/10.1016/j.jaerosci.2016.02.007

28. Kuuluvainen $H$, Rönkkö T, Järvinen A, Saari S, Karjalainen P, Lähde T, et al. Lung deposited surface area size distributions of particulate matter in different urban areas. Atmos Environ. 2016;136:10513.

29. Zuurbier M, Hoek G, Hazel P Van Den, Brunekreef B. Minute ventilation of cyclists, car and bus passengers: An experimental study. Environ Heal A Glob Access Sci Source. 2009;8:1-10.

30. Cozza IC, Zanetta DMT, Fernandes FLA, da Rocha FMM, de Andre PA, Garcia MLB, et al. An approach to using heart rate monitoring to estimate the ventilation and load of air pollution exposure. Sci Total Environ [Internet]. Elsevier B.V.; 2015;520:160-7. Available from: http://dx.doi.org/10.1016/j.scitotenv.2015.03.049

31. Ramos CA, Reis JF, Almeida T, Alves F, Wolterbeek HT, Almeida SM. Estimating the inhaled dose of pollutants during indoor physical activity. Sci Total Environ [Internet]. Elsevier B.V.; 2015;527528:111-8. Available from: http://dx.doi.org/10.1016/j.scitotenv.2015.04.120 
32. Cohen AJ, Brauer M, Burnett R, Anderson HR, Frostad J, Estep K, et al. Estimates and 25-year trends of the global burden of disease attributable to ambient air pollution: an analysis of data from the Global Burden of Diseases Study 2015. Lancet. 2017;389:1907-18.

33. Nishiwaki Y, Michikawa T, Takebayashi T, Nitta H, Iso H, Inoue M, et al. Long-term exposure to particulate matter in relation to mortality and incidence of cardiovascular disease: The JPHC study. J Atheroscler Thromb. 2013;20:296-309.

34. Cao J, Yang C, Li J, Chen R, Chen B, Gu D, et al. Association between long-term exposure to outdoor air pollution and mortality in China: A cohort study. J Hazard Mater. Elsevier B.V.; 2011;186:1594-

35. Beelen R, Hoek G, van den Brandt PA, Goldbohm RA, Fischer P, Schouten LJ, et al. Long-term effects of traffic-related air pollution on mortality in a Dutch cohort (NLCS-AIR study). Environ. Health Perspect. 2008;116:196-202.

36. Hoek G, Krishnan RM, Beelen R, Peters A, Ostro B, Brunekreef B, et al. Long-term air pollution exposure and cardio-respiratory mortality: A review. Environ Heal A Glob Access Sci Source. 2013;12:43-58.

37. Tainio M, de Nazelle AJ, Götschi T, Kahlmeier S, Rojas-Rueda D, Nieuwenhuijsen MJ, et al. Can air pollution negate the health benefits of cycling and walking? Prev Med (Baltim) [Internet]. The Authors; 2016;87:233-6. Available from: http://dx.doi.org/10.1016/j.ypmed.2016.02.002

38. Strasser G, Hiebaum S, Neuberger M. Commuter exposure to fine and ultrafine particulate matter in Vienna. Wien. Klin. Wochenschr. 2018;130:62-9.

39. Ozgen S, Ripamonti G, Malandrini A, S. Ragettli M, Lonati G. Particle number and mass exposure concentrations by commuter transport modes in Milan, Italy. AIMS Environ Sci. 2016;3:168-84.

40. Martins V, Moreno T, Minguillón MC, Amato F, de Miguel E, Capdevila M, et al. Exposure to airborne particulate matter in the subway system. Sci Total Environ [Internet]. The Authors; 2015;511:711-22. Available from: http://dx.doi.org/10.1016/j.scitotenv.2014.12.013

41. Martins V, Moreno T, Minguillón MC, Van Drooge BL, Reche C, Amato F, et al. Origin of inorganic and organic components of PM2.5 in subway stations of Barcelona, Spain. Environ Pollut. 2016;208:125-36.

42. Querol X, Moreno T, Karanasiou A, Reche C, Alastuey A, Viana M, et al. Variability of levels and composition of PM 10 and PM 2.5 in the Barcelona metro system. Atmos Chem Phys. 2012;12:5055-76.

43. Qiao T, Xiu G, Zheng Y, Yang J, Wang L, Yang J, et al. Preliminary investigation of PM1, PM2.5, PM10 and its metal elemental composition in tunnels at a subway station in Shanghai, China. Transp Res Part D Transp Environ [Internet]. Elsevier Ltd; 2015;41:136-46. Available from: http://dx.doi.org/10.1016/j.trd.2015.09.013

44. Vijayan A, Kumar A. Experimental and statistical analyses to characterize in-vehicle fine particulate matter behavior inside public transit buses operating on B20-grade biodiesel fuel. Atmos Environ [Internet]. Elsevier Ltd; 2010;44:4209-18. Available from: http://dx.doi.org/10.1016/j.atmosenv.2010.07.012 
45. Targino AC, Rodrigues MVC, Krecl P, Cipoli YA, Ribeiro JPM. Commuter exposure to black carbon particles on diesel buses, on bicycles and on foot: a case study in a Brazilian city. Environ Sci Pollut Res. Environmental Science and Pollution Research; 2018;25:1132-46.

46. Meng F, Li S, Cao L, Li M, Peng Q, Wang C, et al. Driving Fatigue in Professional Drivers: A Survey of Truck and Taxi Drivers Driving Fatigue in Professional Drivers: A Survey of Truck and Taxi Drivers. 2015;16:474-483.

47. Zhao Y, Zhang J, He X. Risk Factors Contributing to Taxi Involved Crashes: A Case Study in Xi ' an , China. 2015;43:189-98.

48. Wang Y, Li L, Prato CG. The relation between working conditions, aberrant driving behaviour and crash propensity among taxi drivers in China. Accid Anal Prev [Internet]. Elsevier; 2019;126:17-24. Available from: https://doi.org/10.1016/j.aap.2018.03.028

49. Qiu Z, Liu W, Gao HO, Li J. Variations in exposure to in-vehicle particle mass and number concentrations in different road environments. J Air Waste Manage Assoc [Internet]. Taylor \& Francis; 2019;69:988-1002. Available from: https://doi.org/10.1080/10962247.2019.1629357

50. Boogaard H, Borgman F, Kamminga J, Hoek G. Exposure to ultrafine and fine particles and noise during cycling and driving in 11 Dutch cities. Atmos Environ [Internet]. Elsevier Ltd; 2009;43:4234-42. Available from: http://dx.doi.org/10.1016/j.atmosenv.2009.05.035

51. Int Panis L, de Geus B, Vandenbulcke G, Willems H, Degraeuwe B, Bleux N, et al. Exposure to particulate matter in traffic: A comparison of cyclists and car passengers. Atmos Environ. 2010;44:2263-70.

52. Bigazzi AY, Figliozzi MA. Review of Urban Bicyclists' Intake and Uptake of Traffic-Related Air Pollution. Transp Rev [Internet]. Taylor \& Francis; 2014;34:221-45. Available from: http://dx.doi.org/10.1080/01441647.2014.897772

53. Rivas I, Kumar P, Hagen-Zanker A. Exposure to air pollutants during commuting in London: Are there inequalities among different socio-economic groups? Environ Int [Internet]. 2017;101:143-57. Available from: https://linkinghub.elsevier.com/retrieve/pii/S0160412016305803

54. He B, Heal MR, Reis S. Land-use regression modelling of intra-urban air pollution variation in China: Current status and future needs. Atmosphere (Basel). 2018;9:1-19.

55. Zook M, Wollersheim D, Erbas B, Jacobsen KH. Integrating Spatial Analysis into Policy Formulation: A Case Study Examining Traffic Exposure and Asthma. World Med Heal Policy [Internet]. 2018;10:99-110. Available from: http://doi.wiley.com/10.1002/wmh3.258

56. Katanoda K, Sobue T, Satoh H, Tajima K, Suzuki T, Nakatsuka H, et al. An association between longterm exposure to ambient air pollution and mortality from lung cancer and respiratory diseases in Japan. J Epidemiol. 2011;21:132-43.

57. Hansell AL, Bakolis I, Cowie CT, Belousova EG, Ng K, Weber-Chrysochoou C, et al. Childhood fish oil supplementation modifies associations between traffic related air pollution and allergic sensitisation. Environ Heal [Internet]. 2018;17:27-37. Available from: https:// ehjournal.biomedcentral.com/articles/10.1186/s12940-018-0370-5 
58. Ou CQ, Wong CM, Ho SY, Schooling M, Yang L, Hedley AJ, et al. Dietary habits and the short-term effects of air pollution on mortality in the Chinese population in Hong Kong. J Epidemiol Community Health. 2012;66:254-8.

59. Krall JR, Brooke Anderson G, Dominici F, Bell ML, Peng RD. Short-term exposure to particulate matter constituents and mortality in a national study of U.S. urban communities. Environ Health Perspect. 2013;121:1148-53.

60. Wang C, Zhou X, Chen R, Duan X, Kuang X, Kan H. Estimation of the effects of ambient air pollution on life expectancy of urban residents in China. Atmos Environ [Internet]. Elsevier Ltd; 2013;80:34751. Available from: http://dx.doi.org/10.1016/j.atmosenv.2013.08.018

61. Zhu J, Zhang X, Zhang X, Dong M, Wu J, Dong Y, et al. The burden of ambient air pollution on years of life lost in Wuxi, China, 2012-2015: A time-series study using a distributed lag non-linear model. Environ Pollut [Internet]. Elsevier Ltd; 2017;224:689-97. Available from: http://dx.doi.org/10.1016/j.envpol.2017.02.053

62. de Hartog JJ, Boogaard H, Nijland H, Hoek G. Do the health benefits of cycling outweigh the risks? Environ Health Perspect. 2010;118:1109-16.

63. Johansson C, Lövenheim B, Schantz P, Wahlgren L, Almström P, Markstedt A, et al. Impacts on air pollution and health by changing commuting from car to bicycle. Sci Total Environ [Internet]. 2017;584-585:55-63. Available from:

https://linkinghub.elsevier.com/retrieve/pii/S0048969717301559

\section{Figures}



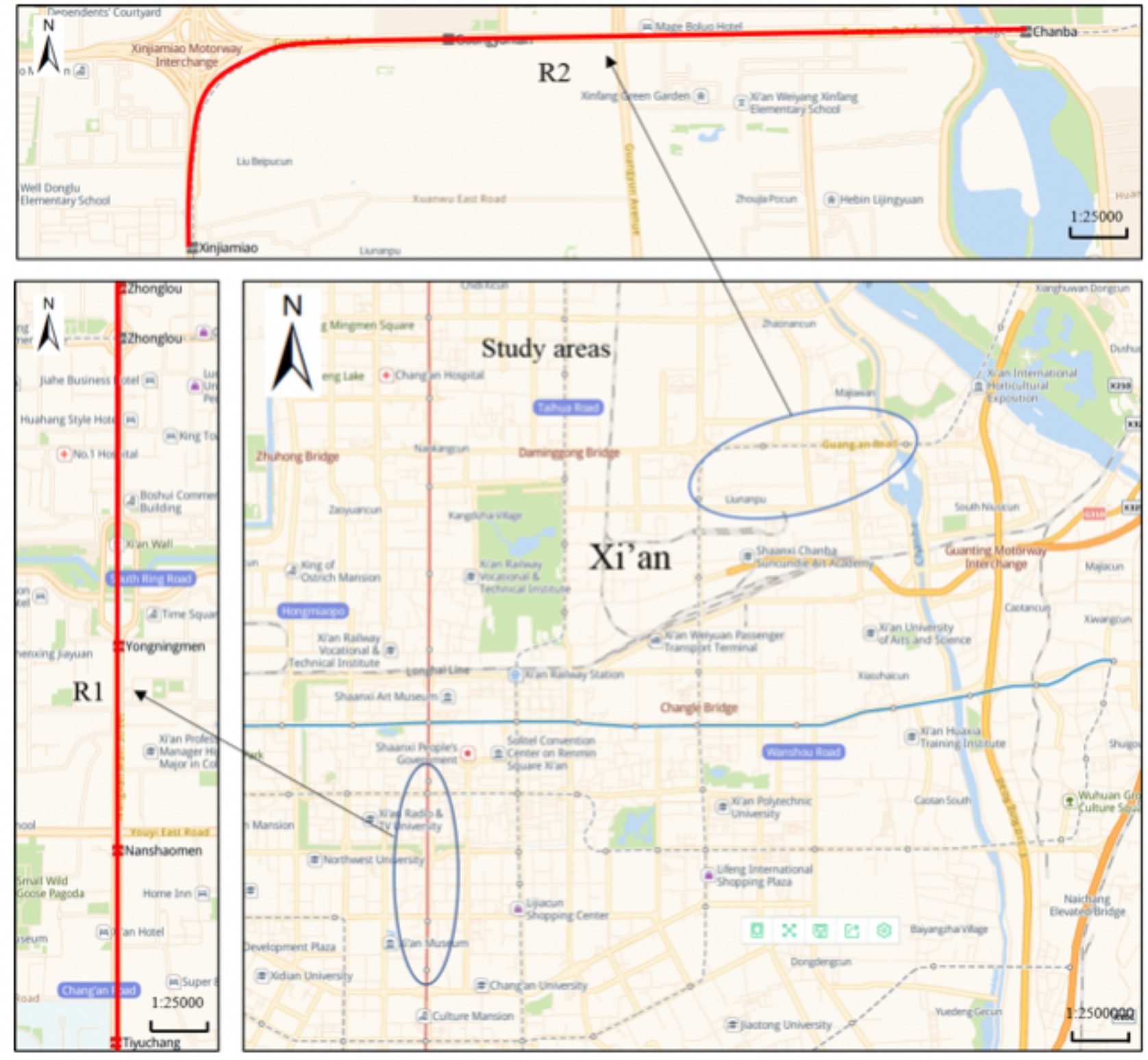

Figure 1

Selected commuting routes and surroundings within Xi'an. Note: The designations employed and the presentation of the material on this map do not imply the expression of any opinion whatsoever on the part of Research Square concerning the legal status of any country, territory, city or area or of its authorities, or concerning the delimitation of its frontiers or boundaries. This map has been provided by the authors. 


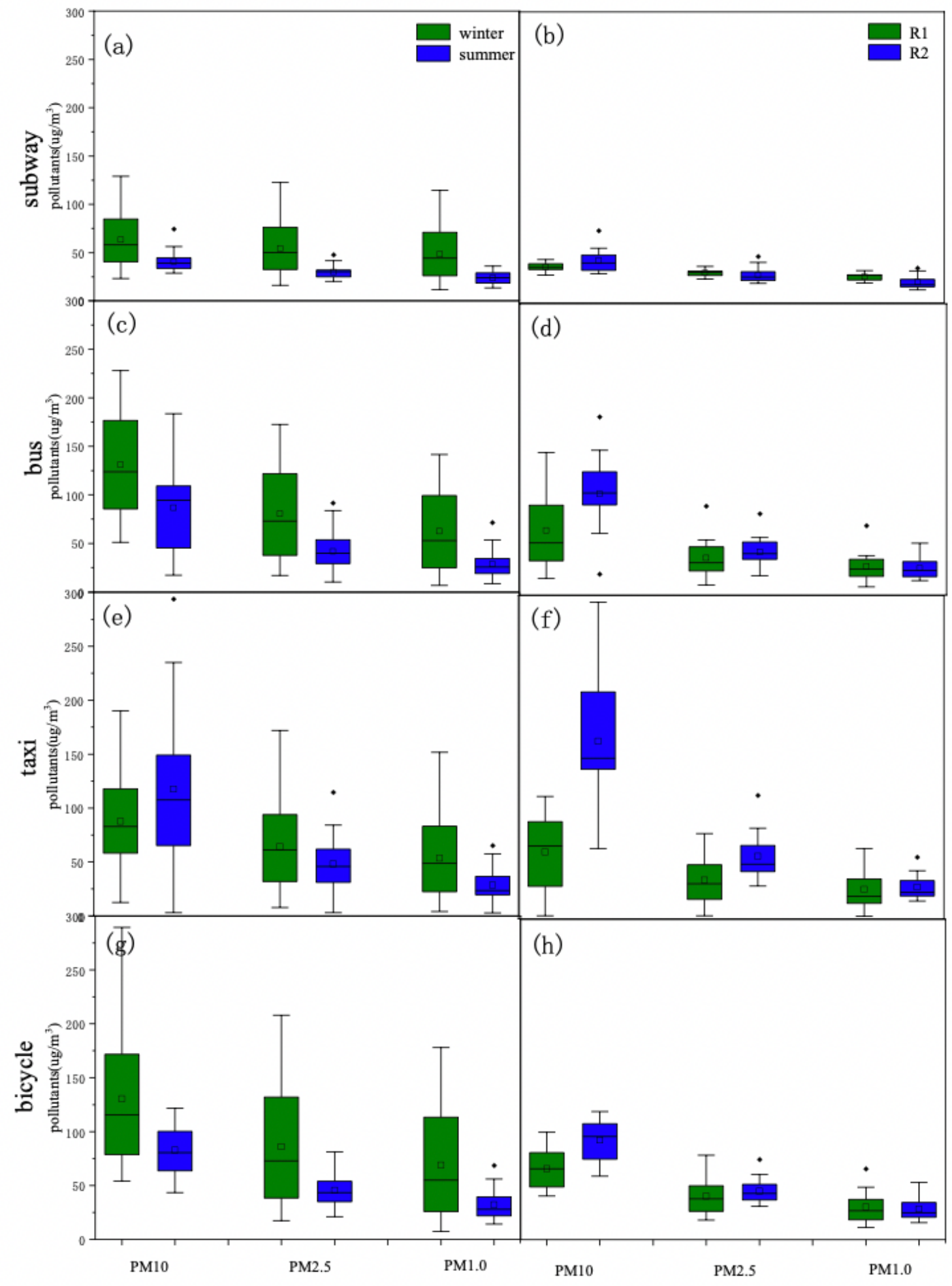

Figure 2

PM10, PM2.5 and PM1.0 mass concentrations of four commuting modes at different routes during different seasons. The 25th (Q1), 50th (median) and 75th (Q3) percentiles are represented by the box range, blank rectangles indicate the average value and whiskers represent Q1-1.5(Q3-Q1) and Q3+1.5(Q3Q1). 

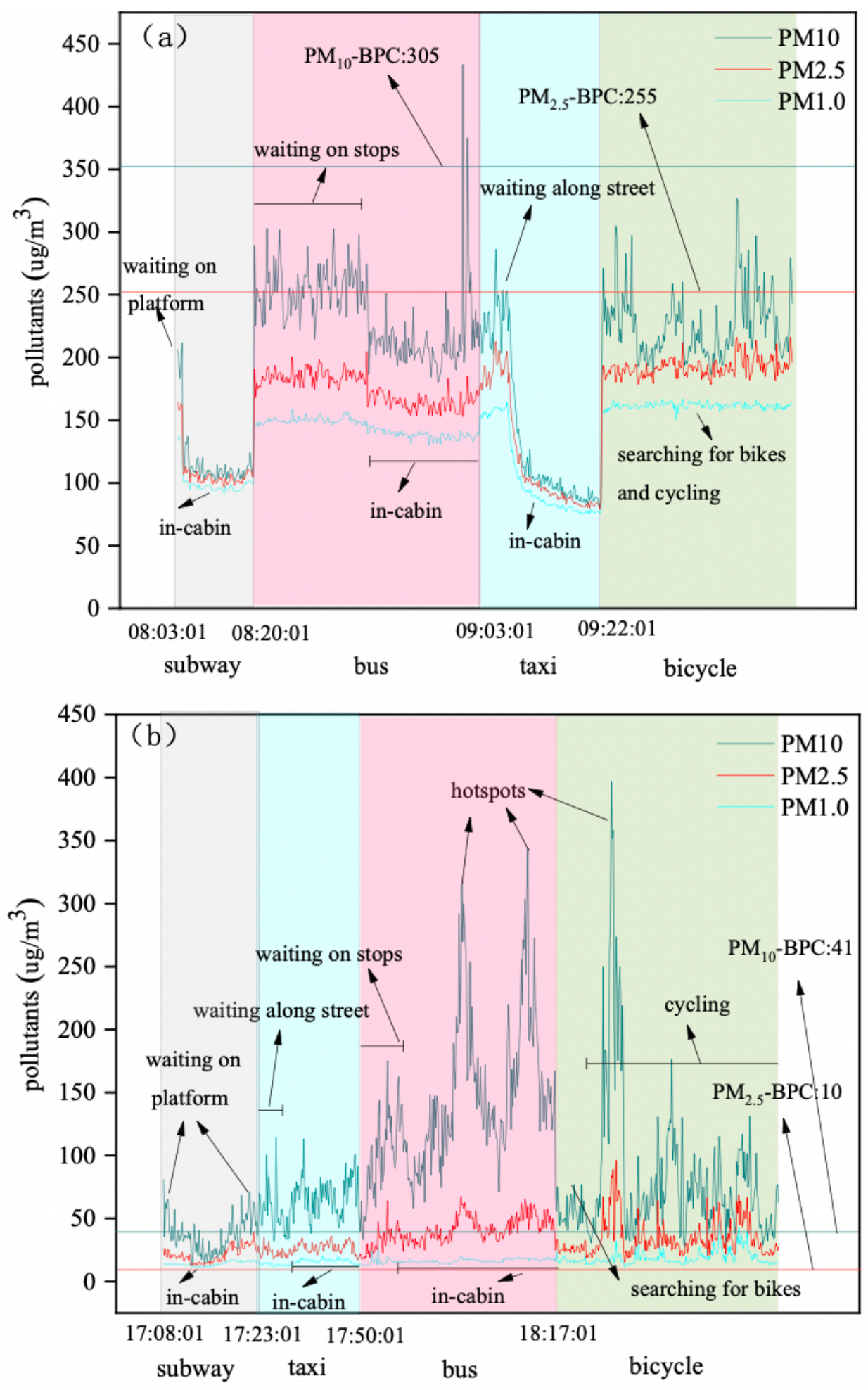

\section{Figure 3}

Time-series plots of PM exposure concentration during single sampling: (a) Jan 12th, 2019 and (b) Sep 20th, 2019; BPC, background pollution concentration 

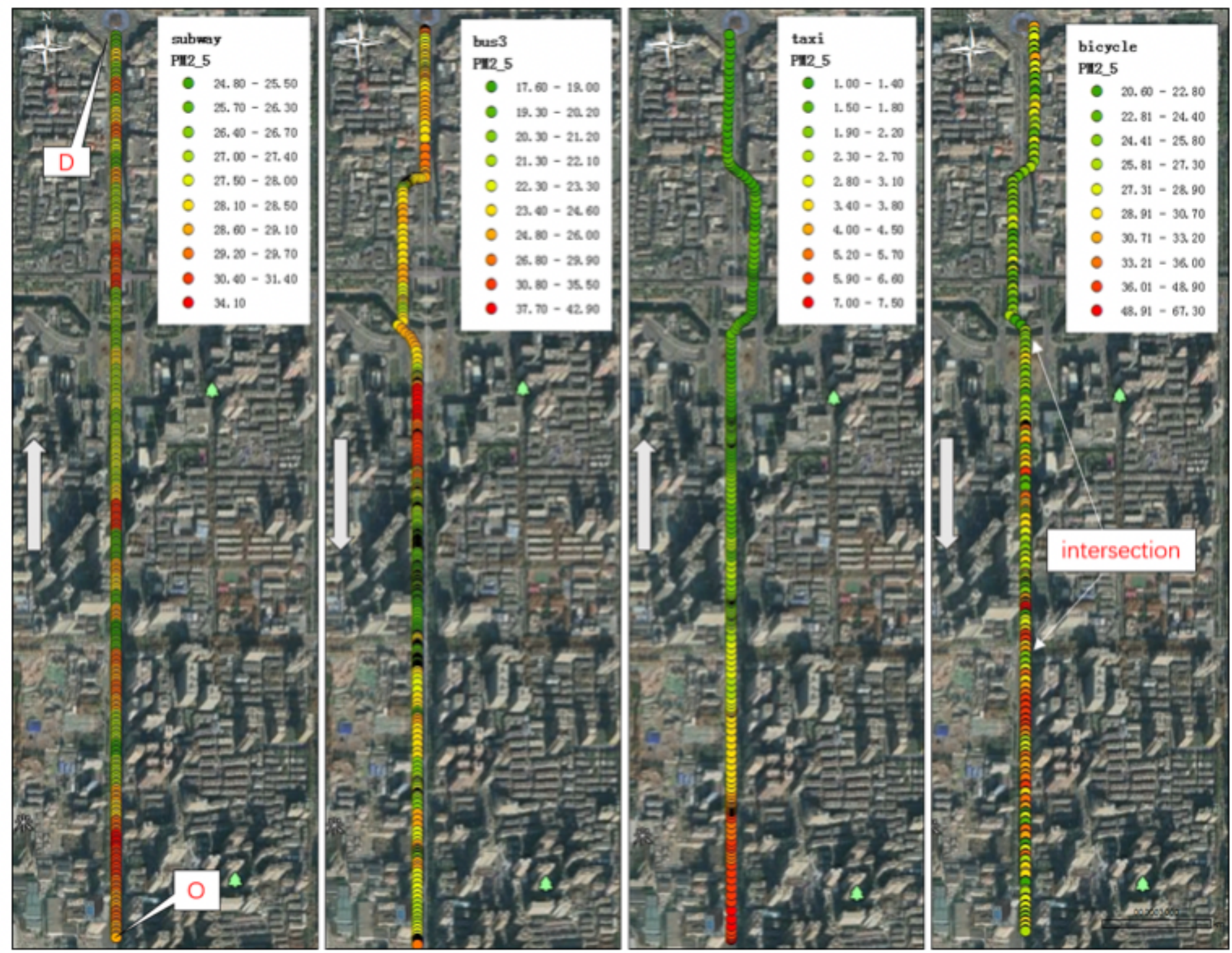

\section{Figure 4}

Spatial patterns of PM2.5 concentration among the four commuting modes. The sampling occurred at Route 1 in the afternoon, 09/06/2019. In the graph, “O”: origin; “D”: destination, and black spots represent places where vehicles stopped, either for boarding or because of congestion. Note: The designations employed and the presentation of the material on this map do not imply the expression of any opinion whatsoever on the part of Research Square concerning the legal status of any country, territory, city or area or of its authorities, or concerning the delimitation of its frontiers or boundaries. This map has been provided by the authors. 

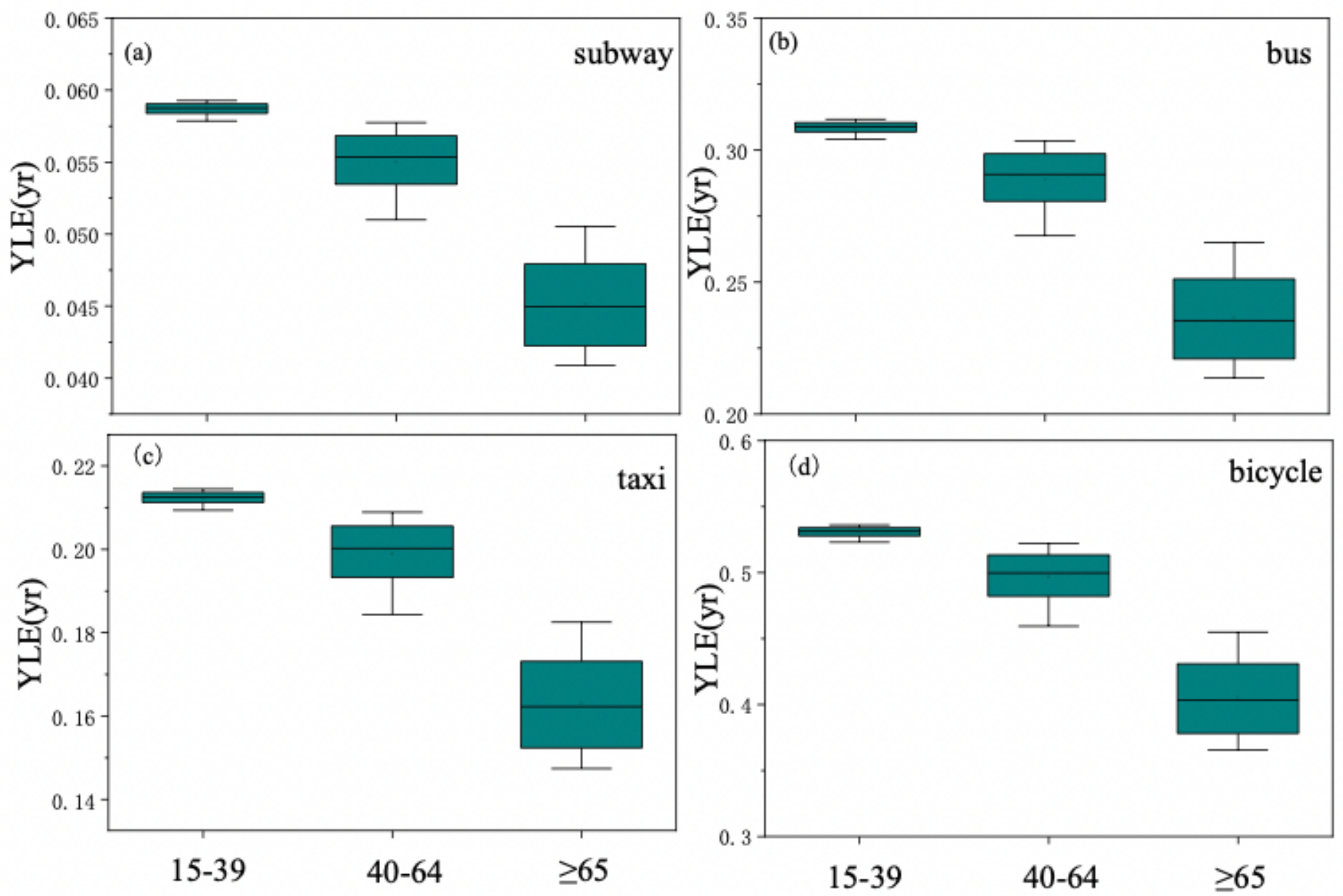

Figure 5

Differences of YLE loss for various life stages during commuting by the four different modes

\section{Supplementary Files}

This is a list of supplementary files associated with this preprint. Click to download.

- SupplementarymaterialsEH.doc

- SupplementarymaterialsEH.doc 